\title{
EDUCAÇÃO POPULAR COMO POLÍTICA DE SAÚDE: interfaces com a formação profissional em saúde ${ }^{1}$
}

\author{
POPULAR EDUCATION AS HEALTH POLICY: interface with training professional in health \\ EDUCACIÓN POPULAR COMO POLÍTICA DE SALUD: interfaces con la formación pro- \\ fesional en salud
}

\author{
Hellen Cristina Sthal \\ Professora Mestre da Universidade Federal de Goiás - UFG, Regional Jataí. \\ Jataí, GO - Brasil. \\ hellen_sthal@hotmail.com \\ Cátia Regina Assis Almeida Leal \\ Professora Doutora da Universidade Federal de Goiás - UFG, Regional Jataí. \\ Jataí, GO - Brasil. \\ catiaassisleal@gmail.com
}

\begin{abstract}
RESUMO: O objetivo deste artigo é debater e problematizar a formação profissional em saúde como um dos fatores determinantes no âmbito dos limites e possibilidades da Educação Popular em Saúde, materializada na Política Nacional de Educação Popular em Saúde no Sistema Único de Saúde (PNEP-SUS). O estudo apresenta abordagem qualitativa e tem a PNEP-SUS como ponto de partida para uma reflexão sobre aspectos da Educação Popular em Saúde e da formação profissional em saúde. São objetos de análise o texto da política na íntegra, a portaria que a institui e o plano operacional do período 2013-2015, além de textos sobre a formação profissional em saúde. Conclui-se que a implementação da Educação Popular em Saúde como política requer, necessariamente, a compreensão ampliada da saúde e de suas determinações sociais e a compreensão e promoção do diálogo, da construção coletiva, da valorização do saber popular e da emancipação. Exige, portanto, a reorientação da formação profissional em saúde, tendo como base a ruptura do paradigma de formação curativista e biologicista, pautada na disciplinaridade e na negação do senso comum.
\end{abstract}

PALAVRAS-CHAVE: Sistema Único de Saúde. Educação Popular em Saúde. Formação profissional em saúde.

ABSTRACT: The purpose of this article is to debate and discuss professional training in health as one of the determining factors within the limits and possibilities of Popular Education in Health, embodied in the National Popular Education Policy in Health in the National Health System One (PNEP-SUS). The study presents qualitative approach and has PNEP-SUS as a starting point for a reflection on aspects of Popular Health Education and of training professional in health. Are objects of analysis of political text in full, the ordinance that establishing and operating plan for the period 2013-2015, as well as texts on vocational training in health. It is concluded that the implementing of Popular Education in Health as policy necessarily requires a broader understanding of health and its social determinants and understanding and promote dialogue, collective construction, the appreciation of popular knowledge and emancipation. Therefore requires the reorientation of vocational training in health, based on the breakdown of curative education paradigm and biologicist, based on disciplinarity and denial of common sense.

KEYWORDS: Health System One. Popular Education in Health. Vocational training in health.

${ }^{1}$ Esta pesquisa contou com financiamento da Fundação de Amparo à Pesquisa do Estado de Goiás (FAPEG).

Artigo recebido em maio de 2017

Aprovado em julho de 2017 
RESUMEN: El propósito de este artículo es debatir y discutir la formación profesional en salud como uno de los factores determinantes en el marco de los límites y posibilidades de la Educación Popular en Salud, materializada en la Política Nacional de Educación Popular en Salud en el Sistema Único de Salud (PNEP-SUS). El estudio presenta un enfoque cualitativo y tiene la PNEP-SUS como punto de partida para una reflexión sobre aspectos de la Educación Popular en Salud y de la formación profesional en salud. Son objetos de análisis el texto de la política en su totalidad, la ordenanza que la instituye y el plan operativo para el periodo 2013-2015, además de textos sobre la formación profesional en salud. Se concluye que la implementación de la Educación Popular en Salud como política requiere, necesariamente, la comprensión ampliada de la salud y sus determinaciones sociales y la comprensión y promoción del diálogo, de la construcción colectiva, de la valoración del conocimiento popular y de la emancipación. Exige, por lo tanto, la reorientación de la formación profesional en salud, basado en la ruptura con el paradigma de formación meramente curativa y biológica, y marcado en la disciplinariedad y en la negación del sentido común.

PALABRAS CLAVE: Sistema Único de Salud. Educación Popular en Salud. Formación profesional en salud. 


\section{1| INTRODUÇÃO}

O debate acerca da reorientação da formação profissional em saúde adquiriu amplitude, principalmente após a criação do Sistema Único de Saúde (SUS), denunciando a incompatibilidade das práticas pedagógicas adotadas na formação dos profissionais de saúde com a proposta de construção coletiva presente nos princípios deste sistema (COSTA; MIRANDA, 2008).

Nas últimas décadas, ganhou espaço a discussão relacionada à importância da Educação Popular em Saúde (EPS), no sentido de se pensar novos caminhos para uma atenção a saúde integral e sintonizada com os valores, saberes e iniciativas populares (BRASIL, 2013a); e sobre a relação direta desta com a formação dos profissionais de saúde.

A Educação Popular (EP) é uma concepção teórica oriunda da área das ciências da educação e se constituiu inicialmente na América Latina, a partir da década de 1960, tendo o educador Paulo Freire como pioneiro de sua sistematização teórica (VASCONCELOS; VASCONCELOS; SILVA, 2015). Na concepção de Freire (1987), o ser humano não pode ser compreendido fora de seu contexto social, ele é o sujeito de sua própria história e formação e se desenvolve por meio da perene reflexão sobre seu lugar no mundo.

A EP não é uma educação "para" o povo, mas sim uma construção compartilhada "com" o povo, um possível caminho para a conscientização e emancipação. É uma prática educativa social na qual se assume estar a favor da promoção da autonomia e do poder de luta do povo, contra todas as formas de injustiça e desigualdade, e não a favor da alienação, da exploração e da manutenção das situações desumanas em que ainda vive uma grande parte da população (SANTORUM; CESTARI, 2011).

A Educação Popular busca trabalhar pedagogicamente o ser humano, fomentar a construção da investigação e do aprendizado, de modo a respeitar a cultura popular e promover a capacidade de análise crítica, de luta e de enfrentamento dos sujeitos. Segundo Brandão (1982), o objetivo da EP não é o condicionamento de indivíduos educadamente submissos, que sejam limpos, alfabetizados, polidos e bebam água fervida, ela objetiva que esses sujeitos tenham subsídios para abrir caminho rumo à conquista da sua liberdade, autonomia e de seus direitos. Para Stotz (2005, p. 25) a Educação Popular é a

[...] educação realizada nos movimentos populares, por meio da participação nas lutas nos mais variados espaços e na dinâmica interna das organizações populares. Trata-se de uma educação política que não se dissocia da vida cotidiana, a qual é base para a compreensão dos problemas no bairro e ponto de partida da reflexão sobre as estratificações sociais e de poder que refletem, no nível local, a estrutura social e política mais ampla.

A área da saúde se aproximou da EP na década de 1970, quando muitos profissionais desta área se engajaram no movimento de luta contra o regime militar. Ocorreram então várias experiências de saúde coletiva com práticas educativas construídas de forma dialogada com a população, como aponta Vasconcelos (2009, p. 32):

Começaram a surgir modos de enfrentamento dos problemas de saúde que mostravam uma surpreendente capacidade de promover a saúde de uma maneira ainda não conhecida na tradição da saúde pública e das várias profissões de saúde, que sempre viram a população como uma massa de carentes que precisava ser ensinada e transformada a partir do saber técnico. Eram práticas extremamente participativas e que contemplavam dimensões e necessidades desprezadas pela medicina oficial. Resultavam em mobilizações comunitárias e movimentos que enfrentavam dimensões coletivas do processo de adoecimento ainda não conhecidas. Formavam pessoas e grupos extremamente ativos e altivos, protagonistas de um modo de ser saudável ainda não vislumbrado pela medicina. 
Muitas destas experiências embasadas na perspectiva da EP surpreenderam pela capacidade de construir, de modo coletivo, ações de grande eficácia e significativo impacto sobre os problemas de saúde, por considerarem os saberes e práticas trazidos pela população, seus interesses e as características da realidade local (VASCONCELOS, 2004).

A partir dessas ações coletivas estruturou-se o Movimento Popular de Saúde (MOPS), cujas ações trouxeram contribuições essenciais para o crescimento e fortalecimento do Movimento de Reforma Sanitária e, consequentemente, para a criação do Sistema Único de Saúde (SUS) em 1988 (VASCONCELOS; VASCONCELOS; SILVA, 2015). O SUS é o conjunto de todas as ações e serviços de saúde prestados por órgãos e instituições públicas federais, estaduais e municipais, da administração direta e indireta e das fundações mantidas pelo Poder Público. A ideia de sistema remete a um conjunto de várias instituições, dos três níveis de governo e do setor privado contratado e conveniado, que interagem para um fim comum. Todos os elementos que integram o sistema referem-se ao mesmo tempo às atividades de promoção, proteção e recuperação da saúde, seguindo os princípios doutrinários de universalidade, integralidade e equidade (BRASIL, 1990).

A participação social teve um importante papel nas formulações da $8^{a}$ Conferência Nacional de Saúde, no sentido da construção e fortalecimento de propostas para a reorientação da política do setor saúde. As discussões iniciadas nesse processo resultaram na conquista institucional da saúde como "direito de todos e dever do Estado", e, posteriormente, deram origem à Lei Orgânica da Saúde, de 1990.

Cabe destacar que a organização estatal tem, muitas vezes, atendido às demandas do avanço do sistema capitalista, de modo que a conquista dos direitos sociais, como saúde, educação e previdência, tem sido basicamente resultante do poder de luta, de organização e de reivindicação de atores e movimentos sociais e nunca uma dádiva do Estado, como às vezes é anunciado.

A participação popular, neste contexto, significa uma força social imprescindível para fazer sair do papel as conquistas e impulsionar as mudanças necessárias. Como se sabe, o interesse de muitos grupos é exatamente o contrário, ou seja, que o serviço público permaneça sempre deficitário, impotente, desacreditado pela própria população que o mantém. (VALLA, 1998, p. 10).

Muitos dos militantes envolvidos no Movimento de Reforma Sanitária, impressionados com as diversas possibilidades da EPS, se organizaram para ter um espaço de reflexão e em 1991 foi criada a Articulação Nacional de Educação Popular em Saúde, que posteriormente, em 1999, passou a se chamar Rede de Educação Popular e Saúde. Em 2002, a educação popular foi incluída formalmente como uma linha de atenção do Ministério da Saúde.

No ano de 2005, a EPS foi redirecionada para a Secretaria de Gestão Estratégica e Participativa (SGEP) e ganhou um papel de destaque na Política Nacional de Gestão Estratégica e Participativa no SUS. A partir da percepção cada vez mais nítida da importância que as práticas de Educação Popular em Saúde possuem no sentido da gestão participativa e do cuidado integral em saúde, foi instituído o Comitê Nacional de Educação Popular em Saúde (CNEPS), que se constituiu como o espaço de apoio à discussão e formulação da Política Nacional de Educação Popular em Saúde no SUS (PNEP-SUS), apresentada em 2012 pelo Ministério da Saúde por meio da SGEP e instituída em 19 de novembro de 2013 pela Portaria $n^{\circ} 2.761$ (BRASIL, 2013b). A política representa, portanto, a materialização legal e institucional de uma luta social que é anterior à própria criação do SUS.

Nesse contexto, o objetivo deste artigo é debater e problematizar a formação profissional em saúde como um dos fatores determinantes no bojo dos limites e possibilidades que a EPS, materializada na PNEP-SUS, traz. 


\section{2| PERCURSO METODOLÓGICO}

O estudo apresenta abordagem qualitativa e tem a PNEP-SUS como ponto de partida para uma reflexão sobre aspectos da Educação Popular em Saúde e da formação profissional em saúde. São objetos de análise o texto da política na íntegra (BRASIL, 2012), a portaria que a institui (BRASIL, 2013b) e o plano operacional do período 2013-2015 (BRASIL, 2013a), além de textos sobre a formação profissional em saúde.

Para a compreensão do objeto em questão tornou-se necessário questionar constitutivos e constituintes do mesmo. Para o estudo documental, recorreu-se inicialmente à análise dos conteúdos da referida política e de seu plano operativo. Dessa forma, o artigo foi tomando corpo a partir da reflexão sobre o conteúdo dos documentos em si e das suas interfaces com a formação profissional e a práxis em saúde, considerando o movimento dialético do objeto e seu contexto sócio-histórico.

Todas as análises, à luz do referencial crítico do materialismo histórico-dialético, foram guiadas pelo entendimento de que a realidade só pode ser compreendida, sem risco de reducionismo ou de superficialidade, por meio da compreensão das relações materiais que lhe deram origem, ou seja, não se pode separar o objeto da dinâmica sócio-histórica que definiu seus contornos, dos condicionantes históricos que influenciaram as relações sociais entre os homens na produção material da existência (MARX; ENGELS, 2009).

\section{3 | A EDUCAÇÃO POPULAR ENQUANTO POLÍTICA DE SAÚDE}

De acordo com a redação da Política Nacional de Educação Popular no SUS (PNEP-SUS), o objetivo principal é "implementar a Educação Popular em Saúde no âmbito do SUS, contribuindo com a participação popular, com a gestão participativa, o controle social, o cuidado, a formação e as práticas educativas em saúde" (BRASIL, 2012, p. 20). Dessa forma, a política pretende promover o diálogo e o compartilhamento de experiências, saberes e práticas, tanto populares quanto científicos, aproximando os indivíduos dos serviços de saúde, da gestão e das práticas mais democráticas e integrais de cuidado.

A EP, direcionada à área da saúde, constitui uma estratégia ímpar para a promoção da ação-reflexão-ação, buscando o cuidado, a formação, o fortalecimento dos atores sociais, o reconhecimento do saber popular e a democratização do SUS. A PNEPS compreende e valoriza a relevância dos saberes e práticas populares e sugere a mediação entre os saberes técnico-científicos e populares, promovendo visibilidade e autonomia aos indivíduos junto à comunidade e aos serviços de saúde. A ideia é pensar projetos educativos "com" as comunidades e não "para" elas.

A política apresenta diretrizes que contemplam os pressupostos filosóficos, éticos e metodológicos da educação popular e buscam "dar sentido e coerência à práxis de educação popular em saúde" (BRASIL, 2012, p. 14): diálogo; amorosidade; problematização; construção compartilhada do conhecimento; emancipação e compromisso com a construção do projeto democrático e popular. Como eixos estratégicos estão descritos: participação, controle social e gestão participativa; formação, comunicação e produção de conhecimento; cuidado em saúde e intersetorialidade e diálogos multiculturais.

Com base nesses eixos, o Plano Operativo elaborado para o período 2013-2015 (BRASIL, 2013a) traça estratégias de implementação da política, sendo que as estratégias relacionadas à questão da formação e produção do conhecimento são: desenvolver processos de formação, pesquisa, extensão na perspectiva da educação popular em saúde; promover a educação popular em saúde junto aos serviços de saúde; contribuir com a produção de conhecimento em educação 
popular em saúde; implementar um plano de comunicação da PNEPS.

Desse modo, a política aborda a questão da formação em saúde enquanto um de seus eixos estratégicos e o plano operativo 2013-2015 busca sua operacionalização por meio das estratégias de ação citadas acima. Contudo, tais ações provavelmente encontrarão dificuldades de implementação diante do cenário nacional da formação em saúde e diante da complexidade de uma formação em saúde para a práxis na perspectiva da educação popular. Esse cenário reforça a importância do debate e problematização acerca das determinações envolvidas, para que se possa caminhar no sentido da materialização e implementação de ações.

Vasconcelos, Vasconcelos e Silva (2015) afirmam que o desafio atual da PNEP-SUS é sua implementação descentralizada nos diversos estados e municípios. E alertam que a perspectiva de trabalho da EP não é algo que se possa generalizar ou implementar por meio de imposições administrativas, "a EP pressupõe uma determinada leitura da realidade e uma intencionalidade política que dependem da livre escolha de cada trabalhador das políticas de saúde" (VASCONCELOS; VASCONCELOS; SILVA, p. 104).

Corroborando com esse debate, Flisch et al. (2014) realizaram uma pesquisa sobre a percepção dos profissionais que atuavam na Atenção Primária à Saúde (APS) sobre a Educação Popular em Saúde e observaram que a maioria dos participantes reconheceu a necessidade de ampliação dos seus conhecimentos sobre a EPS. Grande parte dos profissionais pesquisados relatou que não adotava nenhum referencial teórico em suas ações de educação em saúde e, mesmo quando a pedagogia de Paulo Freire foi mencionada por alguns profissionais, a utilização do termo foi controversa.

Isto, provavelmente, como consequência de seu emprego simplificado, considerando o diálogo como a mera troca de informações entre profissionais e usuários; partindo de uma investigação da realidade sem a apropriação conceitual e analítica e sem a intencionalidade política própria dessa abordagem (FLISCH et al., 2014). De acordo com os autores, os resultados encontrados apontam para a necessidade de qualificação e de formação dos profissionais de saúde para atuarem em ações que visem à obtenção de melhorias na qualidade de vida dos indivíduos e populações, considerando que a saúde é também produto do contexto social e ambiental.

Em um estudo realizado por Bonetti, Odeh e Carneiro (2014), sobre a institucionalização da Educação Popular em Saúde, a dificuldade de compreensão sobre o que seja EPS por parte dos trabalhadores de saúde foi apontada por mais de um entrevistado como sendo um risco na sua institucionalização, o que remete novamente à importância de se debater a questão da formação profissional em saúde para atuação no SUS, na perspectiva da Educação Popular em Saúde.

\section{4 | A FORMAÇÃO EM SAÚdE E A PRÁXIS NA PERSPECTIVA DA EPS: DIVERSAS CON- TRADIÇÕES}

A saúde e a educação constituem práticas sociais, produzidas e reproduzidas ao longo do tempo e espaços históricos. Assim, é fundamental levar em consideração que, durante muito tempo, a educação escolar na sociedade brasileira foi centrada basicamente na figura do professor e transmissão de conhecimentos, chamada por alguns autores de educação bancária (MACIEL, 2009). Apesar da aproximação da área da saúde com os princípios da Educação Popular, ocorrida na segunda metade do século $X X$, os profissionais de saúde ainda tendem a reproduzir em suas práticas educativas em saúde o modelo de educação tradicional com o qual conviveram durante sua formação: 
[...] tem-se assistido, na maioria dos serviços, à reprodução de ações educativas extremamente normatizadoras e centradas apenas na inculcação de hábitos individuais considerados saudáveis. Esta forma de trabalho educativo boicota a participação popular, pois faz calar os sujeitos e afasta as lideranças locais [...]. (VASCONCELOS, 2004, p. 77).

Freire (1996) afirma a necessidade de superarmos este modelo bancário na diversidade das relações humanas e, consequentemente, nos processos educativos. Nesse cenário, a EPS se apresenta como um contraponto às práticas autoritárias e as ações transversais da educação em saúde. Constitui, na contra hegemonia, um possível caminho para a conscientização e emancipação, uma prática educativa na qual se assume que estamos a favor da promoção da autonomia, contra todas as formas de injustiça e desigualdade.

Na contramão dessa proposta de diálogo, emancipação e construção coletiva presente na Educação Popular, a formação dos profissionais de saúde tem atendido, em vários aspectos, a lógica hegemônica do capital e da preparação de recursos humanos para atuar tecnicamente. As políticas de saúde tem historicamente reforçado a medicina científica e racional, "seguindo de perto o modelo internacional de saúde referido pela Organização Mundial de Saúde (OMS) que determina o primado da medicina científica produzida nos países desenvolvidos" (LOYOLA, 1984, p. 226-7).

De acordo com Brasil (2005), existe uma pedagogia inerente ao modo de produção capitalista, que representa uma tentativa de homogeneização social para dissimular a divisão classista que enaltece o projeto da classe dominante como sendo de todos e condiciona os sujeitos para que se possam perpetuar os modelos postos. Dentre os componentes dessa pedagogia a autora destaca: a desqualificação do trabalho, a preponderância da razão instrumental, a cidadania tutelada, o dilaceramento da subjetividade, o consumo em rede e a recente cultura terapêutica, que medicaliza os resultados sociais desastrosos da desigualdade, transformando-as em doenças e culpabilizando os indivíduos.

Desde que o saber cuidar do outro foi expropriado da sociedade e configurado em determinadas técnicas produzidas por determinados atores legalmente reconhecidos como tais, exercidas em determinados lugares e acessível somente a alguns, a dinâmica da vida se reduziu a estar ou não estar doente e esta situação definida com base em normas que determinam o normal e o patológico. E o agenciamento da saúde, como ausência de doença, e desta, como sendo a falta de algo para fazer a máquina humana funcionar (o corpo), reproduz, no imaginário popular, a ideia de saúde restrita ao consumo de serviços e de medicamentos. (BONETTI; PEDROSA; SIQUEIRA, 2011, p. 402).

O paradigma dominante na formação em saúde afirma uma ciência inflexível às reais necessidades humanas, um modelo de racionalidade que vislumbra uma única forma de se atingir o conhecimento verdadeiro: aquela decorrente da aplicação de seus próprios princípios epistemológicos e de suas regras metodológicas. Caracteriza-se como um modelo autoritário, que se opõe duramente ao senso comum e às demais "formas" de ciência (SANTOS, 2010).

Historicamente, a formação dos profissionais de saúde tem sido embasada no uso de metodologias conservadoras, numa perspectiva biologicista de adoecimento e numa abordagem reducionista e fragmentada do conhecimento, com estímulo à disciplinaridade. Assim, diversos profissionais de saúde tem adotado em sua prática profissional no SUS uma postura decorrente desse processo de formação, assumindo uma posição unilateral, colocando-se no centro do processo educativo em saúde e desconsiderando a autonomia dos sujeitos sociais.

Em um estudo de revisão integrativa sobre a formação de recursos humanos para a saúde no Brasil, em que foram analisados 30 trabalhos sobre o tema, as autoras Vendruscolo, Prado e Kleba (2014) afirmam que apesar das iniciativas e ações de fortalecimento da política nacional de 
saúde na direção de um modelo integral, ainda prevalecem diversos problemas no campo da formação dos profissionais, desvelando um significativo distanciamento entre a formação - com orientação biologicista, hospitalocêntrica e conteudista - em relação às práticas interdisciplinares que favoreçam a integralidade e a (co)responsabilidade.

Moretti-Pires (2009) também critica a formação em saúde, fragmentada em disciplinas e especialidades, a qual não se pauta no enfrentamento das determinações sociais de saúde e tem pouca ênfase no SUS. Para o autor, a vivência prática em saúde na comunidade ainda é insuficiente nos currículos dos cursos de graduação da área da saúde, indicando a priorização da técnica e do trabalho individual, focado na doença.

Diversos estudos na área de formação em saúde (GIL, 2005; FEUERWERKER, 2006; CECCIM; FEUERWERKER, 2004; COSTA; MIRANDA, 2009) apontam que a inadequação dos recursos humanos para atuação nos serviços de saúde do SUS deve-se, substancialmente, ao modelo pedagógico hegemônico conteudista e fragmentado e ao modelo biomédico predominante nas práticas tradicionais de saúde, com enfoque na atenção individualizada, especializada, na medicina curativa e hospitalar.

Fato é que os profissionais de saúde — os médicos, sobretudo, mas não exclusivamente - têm enorme dificuldade de admitir que são condicionados pelos objetivos dos grupos ou classes dominantes numa certa época, e que esses objetivos não coincidem com a sua função precípua [...]. (STOTZ, 2005, p. 9).

Conhecer e reconhecer as implicações de viver numa sociedade de classes é um desafio à formação e à prática dos profissionais de saúde, geralmente embasadas num saber técnico e científico construído à margem da vida social e com ilusões de neutralidade política. Também resulta daí a dificuldade em admitir que os dogmas nos quais o seu saber se fundamenta possam ser relativizados. Já a Educação Popular, além de reconhecer a existência de uma sociedade de classes, assume a perspectiva das classes exploradas (STOTZ, 2005).

A EP incentiva a criação e manutenção de espaços de conversa franca, onde as pessoas sintam-se à vontade para expor suas dúvidas, seus interesses e suas considerações. Cabe então questionar se os profissionais de saúde podem ser capazes de criar e manter esses espaços sem terem convivido, na maioria das vezes, com esta concepção de educação em sua formação.

Vasconcelos, Vasconcelos e Silva (2015, p. 91) afirmam que há um grande espaço separando o atendimento dos serviços de saúde da vida cotidiana da comunidade:

A maioria dos profissionais de saúde pouco conhece a dinâmica familiar e comunitária de convivência e enfrentamento dos problemas de saúde, principalmente das classes populares. Para ela, muitas atitudes e falas dos usuários dos serviços, sobre suas estratégias de lidar com seus problemas, parecem desconexas e estranhas.

As atuais propostas de reorientação da formação em saúde destacam a importância da integralidade, da articulação entre teoria e prática e da compreensão da saúde como resultante de múltiplas determinações. Além disso, a recente valorização de metodologias ativas e problematizadoras de ensino tem ampliado espaço para o debate sobre a Educação Popular nos processos de formação em saúde, contudo, de um modo pouco crítico, em que quase não se discute sobre as diversas perspectivas pedagógicas que balizam estas metodologias, representadas principalmente pela pedagogia das competências e pelo lema "aprender a aprender".

Duarte (2010) alerta que a pedagogia das competências é imbuída de uma visão idealista de educação. Idealista na medida em que concebe os problemas sociais como resultados de equívocos 
aleatórios, levando à crença de que a mera difusão de novas ideias entre os indivíduos por meio da educação é capaz de resolver os problemas sociais. Ou seja, não há qualquer perspectiva de compreensão e possibilidade de superação do modo de reprodução capitalista. Ainda de acordo com o autor, "esse idealismo chega ao extremo de acreditar ser possível formar, no mesmo processo educativo, indivíduos preparados para enfrentar a competitividade do mercado e imbuídos do espírito de solidariedade social" (DUARTE, 2010, p. 35).

O modelo de competências é uma via de mão dupla e há significativa tendência de que as competências sejam desenvolvidas para atender apenas ao mercado de trabalho. Diverge, portanto, da concepção dialética de educação presente nos textos do SUS e da PNEPS, que propõem o desenvolvimento das múltiplas capacidades do ser humano, o fortalecimento da consciência de classe para intervir de modo crítico, organizado e criativo na transformação estrutural da sociedade.

Ainda de acordo com Duarte (2001), o "aprender a aprender" representa, para grande parcela dos educadores, um símbolo das posições pedagógicas mais inovadoras, progressistas e, portanto, sintonizadas com o que seriam as necessidades dos indivíduos e da sociedade. No entanto, o autor aponta o papel ideológico desempenhado por esse tipo de apropriação das ideias de Vygotsky, qual seja, o papel de manutenção da hegemonia burguesa no campo educacional, por meio da incorporação da teoria vygotskiana à ideologia neoliberal.

Dentre as principais metodologias ativas difundidas na formação em saúde, ganharam destaque a problematização e a Aprendizagem Baseada em Problemas (Problem Based Learning - PBL). A problematização tem sua origem nos estudos de Paulo Freire (1987), com base na afirmação de que os problemas a serem estudados precisam valer-se de um cenário real. Para esse autor, quanto mais o professor possibilitar aos estudantes perceberem-se como seres inseridos no mundo, tanto mais se sentirão desafiados a responder aos novos desafios. Paulo Freire defende que a educação não pode ser uma prática de depósito de conteúdos apoiada numa concepção de homens como seres vazios a serem "preenchidos" com um saber pronto e imutável, mas de problematização dos homens em suas relações com o mundo. Para tanto, a educação precisa fundamentar-se na relação dialógica entre educador e educando, o que possibilita a ambos aprenderem juntos, por meio de um processo emancipatório.

\begin{abstract}
A problematização não se esgota no encontro compartilhado de uma solução. Ela continua na sua implementação na realidade concreta, gerando novos desafios e reflexões. Os resultados da ação, com suas insuficiências, geram novas problematizações. Os fracassos e sucessos inesperados ensinam dimensões antes não consideradas. Um processo sem fim de reflexão, ação, reflexão, ação... Trata-se, portanto, de uma problematização vinculada à realidade e comprometida com sua transformação, o que não ocorre em muitas metodologias ativas e problematizadoras que são difundidas no setor saúde. (VASCONCELOS; VASCONCELOS; SILVA, 2015, p. 98).
\end{abstract}

Segundo Berbel (1998) a Aprendizagem Baseada em Problemas é o eixo principal do aprendizado teórico do currículo de algumas escolas de Medicina, cuja filosofia pedagógica é o aprendizado centrado no aluno. Constitui-se pelo estudo de problemas propostos com a finalidade de fazer com que o aluno estude determinados conteúdos. Ou seja, os problemas não são oriundos da observação da realidade nem retornam a ela ao final do processo, como na problematização. Não há perspectiva de intervenção social.

A compreensão da EP em sua essência requer dos profissionais de saúde uma formação com caráter humanista, ou seja, uma formação realmente comprometida com a preparação para a vida em sociedade, abrangendo certas dimensões fundamentais desta, como a dignidade pessoal, o reconhecimento do próprio valor como ser humano e do valor dos outros, o desenvolvimento da 
autonomia pessoal, o respeito aos semelhantes e ao meio ambiente, a construção de uma visão de mundo coerente e crítica, uma compreensão temporalmente situada de si e da sociedade em que vive e a orientação mediante valores universais (CENCl; FÁVERO, 2008).

Portanto, é necessário questionar quem é o indivíduo que se pretende formar e qual modelo de educação faz essa mediação. Apesar das iniciativas do Ministério da Saúde de reformulação da formação dos profissionais de saúde - como o Programa Nacional de Reorientação da Formação Profissional em Saúde (Pró-saúde), o Programa de Educação pelo Trabalho para a Saúde (PETSaúde) e o Programa de Incentivos às Mudanças Curriculares dos Cursos de Medicina (Promed) - as mudanças são pequenas e os principais problemas ainda prevalecem, sugerindo que as mudanças feitas são superficiais e insuficientes (BRASIL, 2008). E se essa formação mais ampla, crítica e integral ainda constitui um grande desafio, uma formação para atuação na perspectiva da educação popular, uma perspectiva contra-hegemônica, em sintonia com os princípios trazidos na PNEP-SUS, simboliza um desafio ainda maior.

\section{5 | DIANTE DE TANTOS LIMITES, QUAIS AS POTENCIALIDADES?}

A PNEP-SUS é uma conquista, visto que representa a materialização legal e institucional de uma mobilização e luta social de longa data, anterior a própria criação do SUS. A política, seus eixos e estratégias de implementação trazem um reforço à proposta de mudança de paradigma na práxis em saúde, de superação do modelo biomédico e do ensino tradicional, pressupondo uma reorientação das relações entre profissionais e usuários dos serviços de saúde.

São notáveis os avanços na ampliação dos conceitos de educação e de saúde no SUS, com o desenvolvimento de formas coletivas de atenção à saúde que vão muito além da medicina e da educação tradicionais. A educação popular contribuiu e ainda tem muito a contribuir no processo de crescimento e aprimoramento do SUS e das práticas educativas em saúde. Nesse contexto, a EP pode ser um instrumento para a construção de uma integralidade na assistência à saúde, que possibilite não apenas a abordagem ampliada das diferentes dimensões pessoais, mas também a construção de práticas que integrem as dimensões políticas e econômicas, locais e societárias.

A implementação da PNEP-SUS apresenta potencial para a conquista de uma nova cultura política no SUS, ampliando a democracia participativa, mais identificada e respeitosa com a diversidade da cultura popular brasileira. Construção já em curso no campo das práticas de EPS, mas que agora poderá ser capilarizada, ou seja, possibilitar o alcance aos princípios, valores e "jeitos de fazer" da EPS na vida cotidiana das pessoas. Para esta conquista, é evidente a necessidade de maior investimento público em processos formativos e comunicativos que propiciem aos atores implicados com a implementação da Política, um processo dialógico e pedagógico de fato, promotor de uma rede de interlocutores capazes de contribuir com a sua descentralização junto aos estados e municípios. (BONETTI; ODEH; CARNEIRO, 2014, p. 1420).

A PNEP-SUS não se destina diretamente aos estabelecimentos educacionais formais, ainda que estes estejam voltados para a formação de profissionais de saúde. No entanto, é fato que a EPS reivindica uma ampliação da visão de mundo do profissional de saúde, e, portanto, deve estar inserida em seu processo de formação. A atenção integral à saúde implica a ampliação dos referenciais com que cada profissional de saúde trabalha na construção de seu repertório de compreensão e ação; pressupõe práticas inovadoras em todos os espaços de atenção à saúde, práticas em diferentes cenários e conhecimento da realidade de vida das pessoas bem como de todos os âmbitos do sistema de saúde. 
Santorum e Cestari (2011) defendem que a Educação Popular deve ser assumida desde a universidade na formação de profissionais que virão a atender os usuários do SUS, possibilitando aos estudantes conhecer, fazer, participar, se solidarizar e, enfim, engajarem-se na luta por condições mais justas de saúde e de vida, luta esta que deve ser de todos.

A EP prioriza as práticas pedagógicas junto à população e seus movimentos sociais, em contextos pedagógicos informais, e isto dificulta sua inserção nos espaços formais de ensino em saúde, uma vez a cultura acadêmica hegemônica insiste em manter o conhecimento científico dentro dos muros da universidade e o senso comum fora deles. Nesse sentido, Defende-se a busca pela real aproximação entre a universidade, a comunidade e o Sistema Único de Saúde. Uma aproximação não só enquanto campo de prática, mas que supere a simples utilização da rede de serviços, e suponha uma re-elaboração da articulação entre teoria-prática, do ensino-aprendizagem-trabalho, e principalmente, uma reconfiguração do papel social da instituição universitária.

Essa aproximação traduz-se em uma possibilidade de que professores e alunos possam vivenciar as práticas em saúde, o cotidiano dos indivíduos, família e comunidade; participar na construção de novas possibilidades para o cuidado em saúde que considerem o usuário como um sujeito e protagonista da sua história. Os profissionais de saúde necessitam aprender, desde a graduação, a valorizar o saber local e realizar um trabalho construtivo com ele e não sobre ele. As práticas educativas precisam incentivar o diálogo, a reflexão, a expressão da afetividade, a criatividade e se direcionarem para a formação de sujeitos autônomos e conscientes, sujeitos que poderão realmente participar de forma ativa no processo de formulação e gestão da política pública de saúde.

Na concepção da EP, a prática educativa em saúde supera a relação de ensino/aprendizagem didatizada e assimétrica; vai além da prescrição de hábitos e comportamentos saudáveis; propõe uma relação dialógica de horizontalidade. Aos profissionais da saúde, gestores e usuários dos serviços de saúde cabe a necessidade de um comprometimento ético, diante do qual cada um deles assume um papel de sistematizador da situação de saúde em favor da comunidade, se reconhecendo como parte dela e como sujeitos sociohistóricos envolvidos neste processo de construção.

Além disso, é necessária e urgente a politização da formação em saúde. Concorda-se com Mascarenhas (2005, p. 62) quando esta autora afirma que "educação não é mercadoria e sim um direito social que deve ser garantido a todos", ressaltando que uma formação de qualidade não pode ser balizada por uma ótica reducionista de mercado, que considera apenas os interesses das classes dominantes. 


\section{6| CONSIDERAÇÕES FINAIS}

Existem diversos desafios à efetivação da Política Nacional de Educação Popular no SUS, e a formação profissional é um determinante significativo envolvido nesse processo. Contudo, é preciso reconhecer que a política traz consigo um reforço à proposta de mudança de paradigma na práxis em saúde, uma proposta de superação do modelo biomédico e do ensino tradicional, pressupondo uma reorientação do cuidado em saúde de uma forma geral e das relações entre profissionais e usuários dos serviços de saúde.

O presente estudo abordou a PNEP-SUS enquanto texto redigido, enquanto "política no papel", até mesmo por se tratar de uma política recentemente instituída e cuja implementação ainda está em fase inicial. Nesse sentido de discutir e incentivar a implementação da PNEP-SUS, o SGEP promoveu, em 2014, a realização do Seminário Nacional de Educação Popular em Saúde. O Seminário representou um espaço de debate, trocas de experiências e reflexões sobre a PNEPSUS, e reuniu movimentos populares, educadores, técnicos do MS, gestores e trabalhadores da saúde (MUZI, 2014).

Ainda em 2014 foi realizado o Seminário Nacional de Educação Popular na Formação em Saúde (2014), de 10 a 13 de dezembro em João Pessoa - PB. O Seminário foi pensado pelo movimento de Educação Popular em Saúde para refletir sobre estratégias de ampliação da presença da Educação Popular e avaliar sua contribuição na reorientação da formação profissional em saúde e difusão destes conhecimentos e experiências.

Outra iniciativa que merece destaque é o Programa de Qualificação em Educação Popular em Saúde (EdPopSUS), que visa contribuir para aprimorar a atuação dos profissionais das equipes de Atenção Primária à Saúde, principalmente os Agentes Comunitários de Saúde e Agentes de Combate às Endemias, em relação às práticas educativas de promoção da saúde e da equidade, tendo como referencial político-metodológico a Educação Popular em Saúde. Em sua primeira fase, iniciada em 2014, capacitou profissionais dos estados do Ceará, Piauí, Bahia, Pernambuco, Sergipe, Distrito Federal, Rio de Janeiro, São Paulo e Rio Grande do Sul.

Cabe destacar, por fim, o lançamento do Marco de Referência da Educação Popular para as Políticas Públicas (BRASIL, 2014), promovido pela Secretaria Geral da Presidência da República. O Marco expressa o esforço do Governo Federal para articular os processos educativos/formativos realizados nos múltiplos setores das políticas públicas, como também apresentar um referencial político-metodológico, na busca de fortalecer a participação da comunidade nos espaços de controle social.

Assim, fica nítido que a EP está conquistando espaço, não apenas na área da saúde, mas no âmbito das políticas públicas em geral. E que a implementação da Educação Popular em Saúde como política exige, necessariamente, a compreensão ampliada da saúde e de suas determinações sociais; e a compreensão e promoção do diálogo, da construção coletiva, da valorização do saber popular e da emancipação. Exige, portanto, a reorientação da formação profissional em saúde tendo em sua base a ruptura do paradigma da formação curativista e biologicista, pautada na disciplinariedade e na negação do senso comum. 


\section{REFERÊNCIAS}

BERBEL, N. A. N. A problematização e a aprendizagem baseada em problemas: diferentes termos ou diferentes caminhos? Interface - Comunicação, Saúde, Educação, Botucatu, v. 2, n. 2, p. 139-154, 1998.

BONETTI, O. P.; ODEH, M. M.; CARNEIRO, F. F. Problematizando a institucionalização da educação popular em saúde no SUS. Interface Comunicação, Saúde, Educação, Botucatu, v. 18, p. 1413-1426, 2014. Supl. 2.

BONETTI, O. P.; PEDROSA, J. I. dos S.; SIQUEIRA, T. C. de A. Educação Popular em Saúde como política do Sistema Único de Saúde. Revista de APS, Juiz de Fora, v. 14, n. 4, p. 397-407, 2011.

BRANDÃO, C. R. Lutar com a palavra: escritos sobre o trabalho do educador. Rio de Janeiro: Graal, 1982.

BRASIL, M. N. A pedagogia do capitalismo e seus componentes. In: MASCARENHAS, Â. C. B. (Org.). Educação e trabalho na sociedade capitalista: reprodução e contraposição. Goiânia: Editora da UCG, 2005. p. 9-48.

BRASIL. Conselho Nacional de Secretários de Saúde. A formação de profissionais de saúde em sintonia com o SUS. Brasília, DF: Conass, 2008. Disponível em: $<$ http://www.cosemsms. org.br/files/publicacoes/formacao_profissionais_2008.pdf>. Acesso em: 17 set. 2015.

BRASIL. Lei $n^{\circ} 8.080$, de 19 de setembro de 1990. Dispõe sobre as condições para a promoção, proteção e recuperação da saúde, a organização e o funcionamento dos serviços correspondentes e dá outras providências. Diário Oficial da União, Brasília, DF, 20 set. 1990.

BRASIL. Ministério da Saúde. Secretaria de Gestão Estratégica e Participativa. Plano Operativo da Política Nacional de Educação Popular em Saúde: 20132015. Brasília, DF: MS; Sgep, 2013a. Disponível em: $<$ http://recid.redelivre.org.br/files/2013/05/PLANO_OPERATIVO_PNEPS.pdf>. Acesso em: 12 mar. 2014.

BRASIL. Ministério da Saúde. Secretaria de Gestão Estratégica e Participativa. Política Nacional de Educação Popular em Saúde. Brasília, DF: MS; Sgep, 2012. Disponível em: <http://www.crpsp.org.br/diverpsi/ arquivos/PNEPS-2012.PDF>. Acesso em: 15 ago. 2014.

BRASIL. Portaria n ${ }^{\circ} 2.761$, de 19 de novembro de 2013. Institui a Política Nacional de Educação Popular em Saúde no âmbito do Sistema Único de Saúde (PNEPSSUS). Diário Oficial da União, Brasília, DF, 20 nov. 2013b. Seção 1, p. 62.
BRASIL. Secretaria-Geral da Presidência da República. Marco de Referência da Educação Popular para as Políticas Públicas. Brasília, DF: SG/PR, 2014. Disponível em: <http://conae2014.mec. gov.br/images/pdf/ MarcodeReferencia.pdf>. Acesso em: 10 jan. 2016.

CECCIM, R. B.; FEUERWERKER, L. C. M. Mudança na graduação das profissões de saúde sob o eixo da integralidade. Caderno de Saúde Pública, Rio de Janeiro, v. 20 , n. 5 , p. 1400-1410, 2004.

CENCI, Â. V.; FÁVERO, A. A. Notas sobre o papel da formação humanística na universidade. Revista Pragmatéia Filosófica, Passo Fundo, ano 2, n. 1, p. 1-8, 2008.

COSTA, R. K. de S.; MIRANDA, F. A. N. Formação profissional no SUS: oportunidades de mudanças na perspectiva da Estratégia de Saúde da Família. Trabalho, Educação e Saúde, Rio de Janeiro, v. 6 n. 3, p. 503-518, 2008.

DUARTE, N. O debate contemporâneo das teorias pedagógicas. In: MARTINS, L. M.; DUARTE, N. (Org.). Formação de professores: limites contemporâneos e alternativas necessárias. São Paulo: Editora UNESP; Cultura Acadêmica, 2010. p. 33-50. Disponível em: <http://static.scielo.org/scielobooks/ysnm8/pdf/martins-9788579831034.pdf>. Acesso em: 12 dez. 2015.

Vygotsky e o "aprender a aprender": crítica às apropriações neoliberais e pós-modernas da teoria vigotskiana. 2. ed. Campinas: Autores Associados, 2001.

FEUERWERKER, L. C. M. Por que a cooperação com o SUS é indispensável para os cursos universitários na área da saúde. Revista Olho Mágico, Londrina, v. 13, n. 1, p. 32-38, 2006.

FLISCH, T. M. P. et al. Como os profissionais da atenção primária percebem e desenvolvem a Educação Popular em Saúde? Interface Comunicação, Saúde e Educação, Botucatu, v. 18, p. 1255-1268, 2014. Supl. 2.

FREIRE, P. Pedagogia da autonomia: saberes necessários à prática educativa. São Paulo: Paz e Terra, 1996.

Pedagogia do oprimido. 17. ed. Rio de Janeiro: Paz e Terra, 1987.

GIL, C. R. R. Formação de recursos humanos em saúde da família: paradoxos e perspectivas. Caderno de Saúde Pública, Rio de Janeiro, v. 21, n. 2, p. 49098, 2005. 
LOYOLA, M. A. Medicina popular. In: GUIMARÃES, R. (Org.). Saúde e medicina no Brasil: contribuição para um debate. 4. ed. Rio de Janeiro: Graal, 1984. p. 225-237.

MACIEL, M. E. D. Educação em saúde: conceitos e propósitos. Revista Cogitare Enfermagem, Curitiba, v. 14, n. 4, p. 773-776, 2009.

MARX, K.; ENGELS, F. A ideologia alemã. São Paulo: Expressão popular, 2009.

MASCARENHAS, Â. C. B. Educação, trabalho e política: uma relação inevitável. In: (Org.). Educação e trabalho na sociedade capitalista: reprodução e contraposição. Goiânia: Editora da UCG, 2005.

MORETTI-PIRES, R. O. Complexidade em Saúde da Família e formação do futuro profissional de saúde. Interface Comunicação, Saúde e Educação, Botucatu, v. 13, n. 30, p. 153-66, 2009.

MUZI, D. Um breve relato sobre o Seminário Nacional de Educação Popular em Saúde. Rio de Janeiro, 2014. Disponível em: <http://pensesus.fiocruz.br/umbreve-relato-sobre-o-seminário-nacional-de-educaçãopopular-em-saúde>. Acesso em: 10 fev. 2016.

SANTORUM, J. A.; CESTARI, M. E. A educação popular na práxis da formação para o SUS. Trabalho, Educação e Saúde, Rio de Janeiro, v. 9, n. 2, p. 223-40, 2011.

SANTOS, B. de S. Um discurso sobre as ciências. 13. ed. São Paulo: Cortez, 2010.
SEMINÁRIO NACIONAL DE EDUCAÇÃO POPULAR NA FORMAÇÃO EM SAÚDE. João Pessoa, PB, 2014. Disponível em: <http://seminarioepsformacao.blogspot. com.br>. Acesso em: 22 jan. 2016.

STOTZ, E. N. A educação popular nos movimentos sociais da saúde: uma análise de experiências nas décadas de 1970 e 1980. Trabalho, Educação e Saúde, Rio de Janeiro, v. 3 n. 1, p. 9-30, 2005.

VALLA, V. V. Sobre participação popular: uma questão de perspectiva. Caderno de Saúde Pública, Rio de Janeiro, v. 14, p. 7-18, 1998. Supl. 2.

VASCONCELOS, E. M. Educação popular: de uma prática alternativa a uma estratégia de gestão participativa das políticas de saúde. Physis: Revista de Saúde Coletiva, Rio de Janeiro, v. 14, n. 1, p. 67-83, 2004.

. Victor Valla e o movimento da educação popular em saúde. In: GARCIA, R. L. (Org.). Victor Vincent Valla: companheiro de lutas, de ideias, de vida. Recife: ANPEd; UFPE; CEAD, 2009. p. 31-38.

VASCONCELOS, E. M.; VASCONCELOS, M. O. D.; SILVA, M. O. A contribuição da Educação Popular para a reorientação das práticas e da política de saúde no Brasil. Revista da FAEEBA - Educação e Contemporaneidade, Salvador, v. 24, n. 43, p. 89-106, 2015.

VENDRUSCOLO, C.; PRADO, M. L.; KLEBA, M. E. Formação de recursos humanos em saúde no Brasil: uma revisão integrativa. Educação em Revista, Belo Horizonte, v. 30, n. 1, p. 215-244, 2014. 